\title{
Unitized Attachment Points of a Disk Tool for the Working Bodies of Shearers and Tunnelling Machines
}

\author{
Alexey Khoreshok ${ }^{1}{ }^{1}$, Leonid Mametyev ${ }^{1}$, Valery Nesterov $^{1}$, Aleksandre Tsekhin ${ }^{1}$, and \\ Andrey Borisov ${ }^{1, *}$ \\ ${ }^{1}$ T.F. Gorbachev Kuzbass State Technical University, Department of Mining Machines and \\ Complexes, 650000 Kemerovo, 28 Vesennya st., the Russian Federation
}

\begin{abstract}
An important task in the technological process of a mining enterprise is preparatory mine working performance, as effective operation of an entire mining complex depends on rate and quality of drilling. Therefore, the main factor affecting the performance of the process of underground mining is the correspondence of design and operating parameters of the working bodies of tunnelling machines to mining and geological conditions. The underground mining operations showed that rocks with a strength $\mathrm{f} \leq 10$ and high abrasiveness are to be destroyed with disc tools, providing higher strength, wear-resistant parameter and low dust formation in comparison with cutters. The usage of disk tools on the working bodies of tunnelling machines of selective action is a poorly studied task and requires special research of the questions of destruction, crushing and loading of rocks at reverse working modes. It has been established that researches aimed at design development of an attachment point of a disk tool for arrow-type working bodies of a tunnelling machines is an urgent scientific task. The original technical solutions for the design of the attachment points of disc and cutter tools are proposed to improve the processes of cutting of working bodies in the face massif, dust suppression, sealing and mounting-dismounting operations at the operation of shearers and tunnelling machines.
\end{abstract}

\section{Introduction}

Numerous national [1-7] and foreign researches [8-14] as well as application experience of a disk tool for working bodies of shearers [4-7] and tunnelling machines [1-3, 8-14] show that it is perspective and, in some cases, competitive to the cutting tool application [15-19]. In the researchers conducted by scientists of the Department of Mining Machines and Complexes of T.F. Gorbachev Kuzbass State Technical University, the possibility and prospects of using a disk tool for the working bodies of shearers and tunnelling machines as well as drilling rigs are proved [20].

\footnotetext{
*Corresponding author: borisovau@kuzstu.ru
} 


\section{Researches}

It is necessary to note the special role of the attachment point of a disk tool for a working body of a mining combine, since the efficiency of the destruction of the rock mass, the reliability of the fastening of a disk tool and the stress-strain state of the entire construction depends on its design parameters [1-3].

In the known designs of the working body of the shearers and tunnelling machines, twosupport and one-support bracket assemblies of a disk tool on rigidly fixed support axes are used, while the inner part of the supports can contain damping elements (Fig. 1).

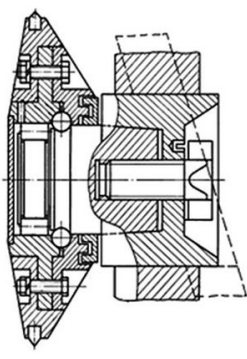

a

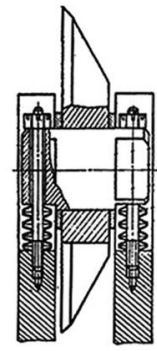

$\mathrm{b}$

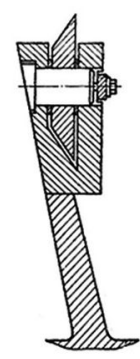

c

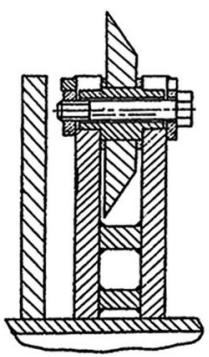

d

d

Fig. 1. The design of the attachment points of disk tools: a - the RF patent 2239059; the USSR author's certificate on invention: $\mathrm{b}-1456558 ; \mathrm{c}-1555481 ; \mathrm{d}-1280119$

The disadvantages of the constructions of two-support attachment points on the crowns of arrow-type tunnelling machines include the following: the probability of gumming between support spaces of the attachment points of a disk tool with products of destruction and then jamming; the implementation of the loading process only if there is one-way (irreversible) direction rotation of the crown; the complex installation and dismantling of the attachment points of a disk tool [1].

\section{Results and discussion}

The analysis of the mining equipment development shows that there is no information about the combination of the processes of destruction, crushing of oversize material and loading of the destroyed rock mass with the implementation of operation reversible modes of the crowns for the working body of tunnelling machines of selective action with a disk tool in well-known scientific research and design developments.

To realize this direction of improving the design of tunnelling machines of selective action at the Department of Mining Machines and Complexes of T. F. Gorbachev KuzSTU the patent researches were conducted: on integration of arrow-type working bodies with radial crowns (Fig. 2); on usage of a disk tool for working bodies of mining and construction machines (Fig. 3).

As a result, technical solutions with bracket assemblies' attachment points of a disk tool to polygonal prisms of arrow-type working bodies of tunnelling machines were proposed and developed [1-3]. The basic design of two-crown arrow-type working body with a disc tool on trigonal prisms according to the Russian Federation patent № 2455486 can be recommended for installation for national and foreign tunnelling machines of selective action. This will increase the efficiency of mining by combining the processes of destruction of the face, crushing of oversize material and loading products of destruction on 
the feeder table across the width of the workings. As an example, Fig. 4 presents the design of the attachment points of a disk tool to trigonal prisms [1].

It is advisable to use cantilever restraint of a disk tool to the face edges of the trigonal prisms located on the reversible combine crowns. The inner space of the prism becomes free and it is the most protected against the destruction products; it is possible to install the hydraulic circuit of the irrigation system to supply the dust-suppressing liquid to the zone of destruction of the face massif with disk tools.

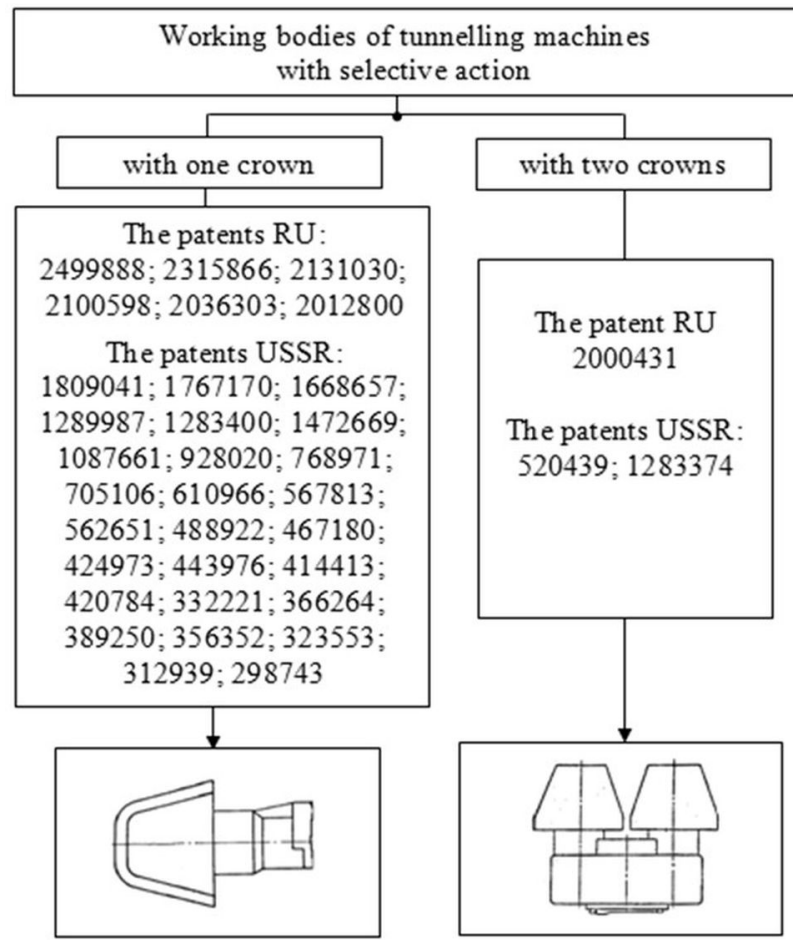

Fig. 2. The working bodies with radial crowns

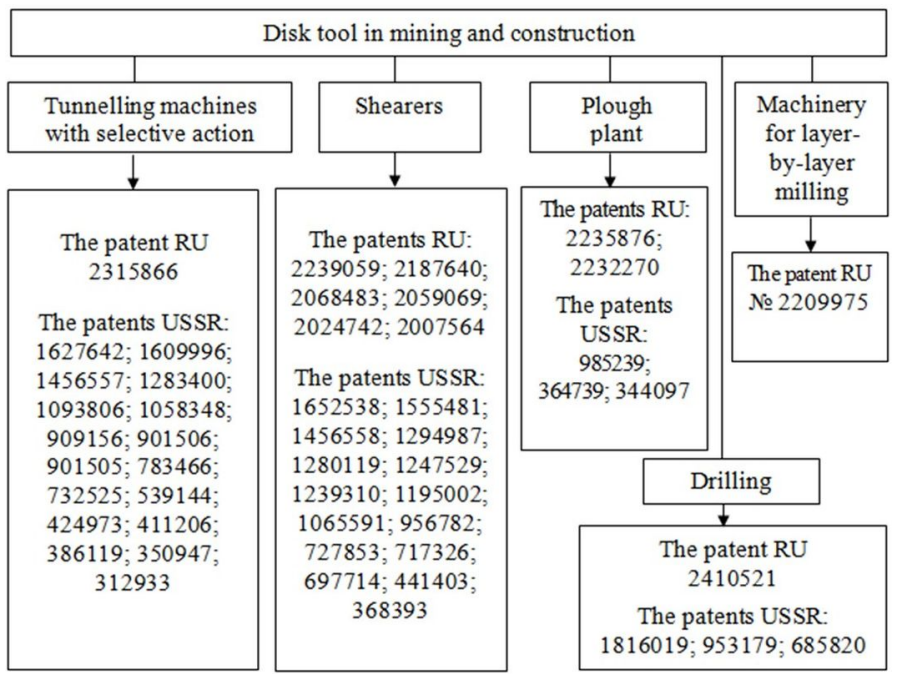

Fig. 3. The disk tool on working bodies of mining and construction machines 


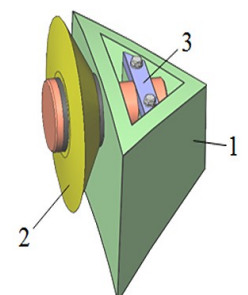

a

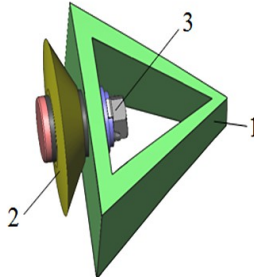

b

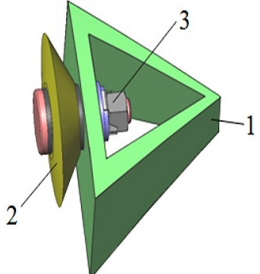

Fig. 4. Fixation of a disc tool to the trigonal prisms: a - plate-lock; $b$ - machine screw; $c-$ nut; 1 - prism; 2 -disc tool; 3 - attachment point

The modular blocks design development with the cantilever attachment points of a disk tool on the polygonal prisms of the bodies of the working bodies of tunnelling machines in order to reduce the gumming and improve the efficiency of the process of assembly and dismantling operations when replacing disk tools in the face is perspective and important researches.

The Department of Mining Machines and Complexes of T. F. Gorbachev KuzSTU carries out researches to develop the advanced technical solutions, ensuring the realization of reversible modes of operation by working bodies of tunnelling machines, shearers and drill mining machines to determine the effective limits of disk tools application according to the strength of the destructible face massif. These researches are urgent for usage of a wide range of national and foreign mining machines for operation in difficult mining and geological conditions at the mines of "SUEK-Kuzbass".

Significance and validity of the problem are proved by the number of contractual and scientific works results, within the framework of the basic part of the state order of Russia Ministry of Education and Science project № 632 "Investigation of technologies and techniques parameters for selecting and developing innovative designs to improve operating efficiency of multipurpose mining machines in Kuzbass".

The directions of design improvement of working bodies of modern national and foreign tunnelling machines of selective action are offered, arranging the combination of the processes of destruction of the face massif with the crushing of oversize material in the press zone and transportation of destruction products from the borehole zone on the receiving board of the loading device [1-3].

To improve the cutting processes, dust suppression, sealing and mounting-dismounting operations of the attachment points of a rock cutting tool on a polygonal prisms of the working bodies of the multipurpose mining machines the implementation of original technical solutions in the form of the Russian Federation patents № 2455486, 128898, $134586,136086,138704,141339,146845,149617,152701,183759,187566$ is recommended.

The usage of original attachment points of modular blocks fixation of a disk tool on trigonal prisms to the working bodies of shearers and tunnelling machines in the framework of the technical solution according to the Russian Federation patent № 149617 is of high importance. Ways of its implementation are shown in Fig. 5. 


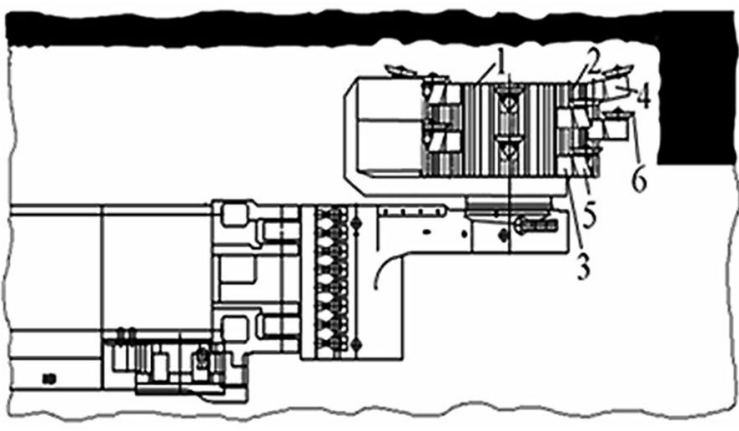

a

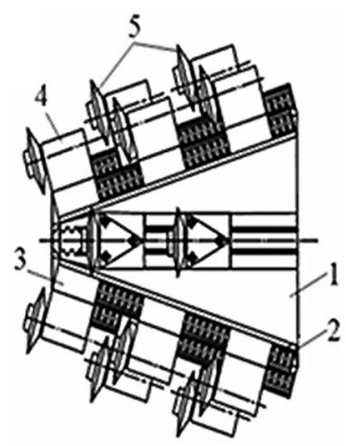

b b

Fig. 5. The constructive schemes of the reversible working bodies with a disk tool on rack and wire attachment points: $a$ - to a multifaceted hob-prism for a shearer; $b$ - the multi-faceted hob-pyramid for tunneling machine

These options characterize the expansion of operational capabilities through the implementation of operational reversible modes when choosing rational schemes of a set of disk tools on trigonal loading prisms. Moreover, the improvement of repair conditions, mounting-dismounting operations in the borehole spaces are additionally provided.

The reversible working body of a shearer (Fig. 5, a) includes a hob with body 1 , made in the form of a polygonal prism. Rails 2 with lateral gear rack bars are rigidly attached to each side of the body 1 ; supports 3 of the $\Pi$-shaped of slope 4 and linear 5 trigonal prisms with disk tools 6 are attached to the rails with a certain step towards each other.

The reversible working body of a tunneling machine (Fig. 5, b) includes a hob with a body 1, made in the form of a polygonal pyramid. Rails 2 with lateral gear rack bars are rigidly attached to each side of the body 1 ; supports 3 of the $\Pi$-shaped of slope 4 and linear 5 trigonal prisms with disk tools 6 are attached to the rails with a certain step towards each other.

For several decades, tunnelling machines of selective action with arrow-type telescopic working bodies were created with the capabilities of collaring or side cutting in face rock massif in the augering machine mode [20]. The research results of the scientific school, organized at the Department of Mining Machines and Complexes at T.F. Gorbachev KuzSTU by professor M.S. Safokhin on the design and development of augering technologies, machines and tools (author's certificate on inventions, USSR: 1513090, 1613560, 1701903; the Russian Federation patents: 2026977, 144475), are efficient to be used for the development of this scientific direction.

\section{Conclusion}

The usage of unified cantilever attachment points of a disk tool to trigonal prisms is recommended, which provide reversible operation on the working bodies of tunnelling machines of selective action and shearers with screw and drum working bodies on horizontal rotation axes.

It is established that two crowns working bodies of tunnelling machines of selective action with radiating crown, equipped by a multi-way spiral intermittent lines in the set scheme of a trigonal prisms with the cantilever attachment points of disk tools in kinematically connected reversible modes of operation, provide a combination of the processes of destruction, the crushing of oversize material and loading of the destroyed rock mass on the table of the feeder across the width of the mine workings. 


\section{References}

1. A.A. Khoreshok, L.E. Mametev, A.Yu. Borisov, A.V. Vorobev, Appl. Mech. Mater. 770, 429 (2015)

2. A.A. Khoreshok, L.E. Mametev, A.Yu. Borisov, A.V. Vorobev, Appl. Mech. Mater. 770, 434 (2015)

3. A.A Khoreshok, L.E. Mametyev, A.Yu. Borisov, A.V. Vorobyev, IOP Conf. Ser.: Mater. Sci. Eng. 91, 012084 (2015)

4. B.L. Gerike, P.B. Gerike, V.I. Klishin, A.P. Filatov, J. Min. Sci. 44:5, 497 (2008)

5. B.L. Gerike, P.B. Gerike, A.P. Filatov, V.I. Klishin, J. Min. Sci. 42:6, 610 (2006)

6. P.B. Gerike, M.A. Belikov, J. Min. Sci. 39:2, 162 (2003)

7. B.L. Gerike, V.I. Klishin, P.B. Gerike, J. Min. Sci. 52:3, 481 (2016)

8. Y. Zhang, X.W. Wang, H.F. Liu, Appl. Mech. Mater. 487, 513 (2014)

9. X.H. Li, W. Du, Z.L. Huang, W.L. Fu, Appl. Mech. Mater. 127, 385 (2011)

10. K. Yang, Y. M. Xia, Y. S. Wu, Appl. Mech. Mater. 508, 159 (2014)

11. A.N. Zhang, Z.F. Zhu, F. Zhu, Adv. Mater. Res. 791:793, 742 (2013)

12. F.H. Li, Z.X. Cai, Y.L. Kang, Appl. Mech. Mater. 90:93, 2232 (2011)

13. L.T. Man and S. J. Li, Adv. Mater. Res. 366, 224 (2012)

14. K.R. Hong et al., Adv. Mater. Res. 399:401, 2116 (2012)

15. X. J. Li et al., Appl. Mech. Mater. 556:562, 498 (2014)

16. S.A. Prokopenko, V.S. Ludzish, I.A. Kurzina, J. Min. Sci. 52:1, 153 (2016)

17. S. Prokopenko, A. Sushko, I. Kurzina, IOP Conf. Ser.: Mater. Sci. Eng. 91, 012058 (2015)

18. S.A. Prokopenko, Appl. Mech. Mater. 682, 319 (2014)

19. P.D. Krestovozdvizhensky, V.I. Klishin, S.M. Nikitenko, P.B. Gerike, J. Min. Sci. 51:2, 323 (2015)

20. L. Mametyev, Yu. Drozdenko, O. Lyubimov, The 8th Russian-Chinese Symposium. Coal in the 21st Century: Mining, Processing and Safety, 50 (2016) 